\title{
The Prevalence and Pattern of Non-Medical Use of Prescription Drugs in Abakaliki, Southeast, Nigeria
}

\author{
Okechukwu B. Anozie ${ }^{* 1,2}$, Nwafor I. Johnbosco ${ }^{1}$, Chidi U. Esike ${ }^{1,2}$, Chukwuemeka I. Ukaegbe ${ }^{1,2}$, \\ Ifeanyi E. Enyanwuma ${ }^{3,4}$, Ifediri E. Nwokporo ${ }^{5}$, Richard L. Ewah ${ }^{6}$ \\ ${ }^{1}$ Department of Obstetrics and Gynaecology, Federal Teaching Hospital, Abakaliki, Ebonyi State, Nigeria \\ ${ }^{2}$ Department of Obstetrics and Gynaecology, Ebonyi State University, Abakaliki, Ebonyi State, Nigeria \\ ${ }^{3}$ Department of Surgery, Federal Teaching Hospital, Abakaliki, Ebonyi State, Nigeria \\ ${ }^{4}$ Department of Surgery, Ebonyi State University, Abakaliki, Ebonyi State, Nigeria \\ ${ }^{5}$ Department of Sociology/Psychology/Criminology and Security Studies, Alex Ekwueme Federal University, Ikwo \\ ${ }^{6}$ Department of Anasthesia, Federal Teaching Hospital, Abakaliki, Ebonyi State, Nigeria
}

*Corresponding Author: Dr. Okechukwu Bonaventure Anozie; okayanoziey2k@ yahoo.com

Received 30 June 2019;

Accepted 18 July 2019;

Published 25 July 2019

\begin{abstract}
Introduction: The growing of non-medical use of prescription drugs is a global health problem and it has emerged as a particularly dangerous health-behavior among young people. However studies assessing misuse among people in Abakaliki are non-existent. Aim: To determine the prevalence and pattern of non-medical use of prescription drugs in Abakaliki. Materials and method: This was a cross-sectional study that involved 420 participants. The respondents completed an anonymous, self-administered questionnaire assessing past-year prevalence and pattern of non-medical use of five classes of prescription drugs. The data was analyzed using SPSS version 20. $\underline{\text { Results: }}$ The prevalence of nonmedical use of prescription drugs in this study was 38.3\%. The mean age of the participants was $22.2 \pm 3.8$ years with majority of them (38.3\%) being within the 19-25 years age bracket. The majority of participants were males $(52.1 \%)$ whereas female accounted for $47.9 \%$ of the respondents. Pain medications such as tramadol, codeine and morphine accounted for majority (73.8\%) of unprescribed medication abused by the respondents. This is followed by other medications such as ibuprofen which was $45 \%$. Sleeping medications and stimulants accounted for $28.3 \%$ and $27.4 \%$ of unprescribed drugs respectively. Similarly, pain medication accounted for majority (74.8\%) of prescribed medicines used by the participants for non medicinal purposes. The least abused class of drugs in the prescribed category were sedative/anxiety medications which accounted for just over $18 \%$. To relax or relieve tension is the most common reasons $(20.5 \%)$ for use of drugs for non medical purposes reported in this study. Other reasons include to improve concentration (16.7\%), to get high (10.7\%) and for recreation (6.9\%). Conclusion: This study shows high prevalence of non medical use of prescription drugs among our study participants in Abakaliki.
\end{abstract}

Keywords: prevalence, pattern, non-medical use, prescription drugs, Abakaliki, Nigeria.

\section{Introduction}

Prescription drugs have in recent past shown a heightened nonmedical use. ${ }^{[1]}$ Its abusers have leveraged on the efforts of health agencies and practitioners to make drugs readily available for prescription medications. ${ }^{[2]}$

The monitoring gaps in their use for medical purposes have also created numerous opportunities to be used in manners, reasons and time not approved by medical practitioners or its diversion to people to whom it has not been prescribed. ${ }^{[2]}$ Despite the existence of control treaties like the 1961 Single Convention on Narcotic Drugs as amended in 1972, the Convention of Psychotropic Substances of 1971, the 1988 United Nations Convention against illicit traffic in Narcotic Drugs and Psychotropic Substances; prescription drugs have remained diverted into illicit channels for non-medical use. ${ }^{[3]}$ In Nigeria, the 2018 National Drug Use Survey shows that about 14.3 million people aged between 15 and 64 years use drugs. Out of this, 4.6 million people use prescription drugs like tramadol and cough syrups for non-medical purposes. ${ }^{[4]}$ This is twice the global average of 5.6 percent. ${ }^{[5]}$ These therefore have attracted the attention of policy makers, researchers, development partners and non-governmental organizations. ${ }^{[6]}$

Opioids, central nervous system depressants, synthetic prescription stimulants, benzodiazepines, and central nervous stimulants are the common types of prescription drugs used for non-medical purposes. ${ }^{[7]}$ In the past 12 months in Nigeria, tramadol, codeine, morphine and cough syrups were commonly used for non-medical purposes. ${ }^{[4,8]}$ The non-medical use of the above drugs cannot be overlooked because it has created high demand for prescription medications. It has also led to new sources of diverting them from 
medical to non-medical use and the production of counterfeit drugs. ${ }^{[8]}$ For non-medical use according to the United Nations Office on Drugs and Crime, prescription drugs are gotten by obtaining prescriptions or prescription drugs from family and friends, over prescribing by physicians, multiple prescriptions through a doctor, forged prescriptions, illegal online pharmacies, theft and burglary (from hospitals, residences, pharmacies) and unscrupulous physicians selling drugs. ${ }^{[9]}$

It has been suggested that prescribed drugs are used non-medically for recreation, to achieve mood enhancing effects such as increasing the effects of illicit drugs or alcohol, self-medication of illness, injury, or drug dependence, reduction of withdrawal symptoms from illicit drugs or alcohol, and to improve performance. ${ }^{[10]}$

Issues of non-medical use of prescription drugs are multi-faceted therefore, difficult to capture the target population engaged in nonmedical use of prescription drugs. ${ }^{[11-15]}$ Prescription drugs are widely accessible because their prescription is believed to be legal and socially acceptable. Furthermore, its study and evaluation have proven to be distinctive as it cannot be viewed from the lens of illicit (or harmful) drug use or drug injecting practices. ${ }^{[16]}$ The nonmedical use of prescription drugs in Nigeria has been underresearched. Due to the limited information on the phenomenon, the scale of the problem has remained unknown, hence the significance of this study. Therefore, the aim of this study was to determine the prevalence and pattern of non medical use of prescription drugs among residents of Abakaliki, Ebonyi State, Nigeria.

\section{Materials and Method}

Study area: Ebonyi state is one of the five states in the South-east geopolitical zone of Nigeria. It was created in 1996 from the largely rural areas of the pre-existing Enugu and Abia States. It has three senatorial districts and 13 Local Government Areas (LGAs). One (Abakaliki) of the LGAs is urban, the other LGA is semiurban and the rest are rural. It has an estimated population of 2.1 million people and occupies a land mass of $5932 \mathrm{~km}^{2}$, sharing boundaries in the west with Enugu State , Cross-River in the East, Abia state in the south and Benue State in the North. ${ }^{[17]}$ The population comprise mainly subsistence farmers and petty traders. Christianity forms their major religion and they are predominantly Igbo Speaking. There are several government owned institutions of higher learning in the state which includes: Ebonyi state university, Alex Ekwueme Federal University, Akanu Ibiam Federal Polytechnic and School of Health Technology.

Study design and population: The study design was a population based descriptive cross-sectional study. The study population comprised people living in Abakaliki.

Selection criteria: Only permanent residents of Abakaliki were enrolled and interviewed.

Sample size determination: Sample size was calculated using the formula for single proportion in study populations. ${ }^{[18]}$

$\mathrm{n}=\mathrm{Z} 2 \mathrm{P}(1-\mathrm{P}) / \mathrm{d}^{2}$,

Where $\mathrm{n}$ is the minimum sample size, $\mathrm{Z}$ is the standard normal deviate at $95 \%$ confidence interval (1.96), $\mathrm{P}$ is the proportion of stimulant use in previous study $(0.62)^{[23]}$ and $d$ is the level of precision required, set at 0.05 . The calculated sample size was 362 . Considering a potential non-response rate of $10 \%$, the minimum sample size required for this study was 398 , however, 500 residents of Abakaliki were enrolled in this study with 420 giving their consent to participate.

Sampling technique: A multi-stage sampling technique was used in the selection of the study participants. The first stage involved the stratification of the streets within Abakaliki town. The second stage involved the selection of the different streets using simple random sampling by balloting. The third stage involved the selection of the buildings within the streets and this was done using simple random sampling technique.

Data collection instrument: Non-medical use of medications was defined as the consumption or in-take of (prescription) drugs as against the ways, purposes and time approved by a medical practitioner or by an individual other than whom it was prescribed. The questionnaire; pretested, semistructured and anonymously self-administered comprised three sections including: (1) sociodemographic characteristics of respondents, (3) the use of prescription drugs for non medical reasons. The drugs assessed for use by the respondents were sleeping medication (Zolpidem, Temazepam, Triazolam), sedative/anxiety medication (Alprazolam, Clonazepam, Diazepam, Lorazepam, Flurazepam), Stimulant medication (Caffeine, Methylphenidate, Dextroamphetamine, Adderall), (3) the pattern of utilization of non prescription drugs.

Data analysis: The data were scrutinized and entered into the computer. Data cleaning was done by carrying out range and consistency checks. Descriptive and analytical statistics of the data were carried out using Statistical Package for Social Sciences (SPSS) IBM Window version 20. Descriptive data were presented as frequencies and percentages. A p-value of $\leq 0.05$ was considered statistically significant.

Ethical issues: Ethical approval was gotten from the Ethics Committee of Alex Ekwueme Federal University Teaching Hospital, Abakaliki, Ebonyi State, Nigeria. All recruited respondents gave informed verbal consent. They were assured of the confidentiality of the information provided.

\section{Results}

This study involved 420 respondents. The mean age of the participants was $22.2 \pm 3.8$ years with majority of them $(38.3 \%)$ being within the 19-25 years age bracket. The majority of participants were males $(52.1 \%)$ whereas female accounted for $47.9 \%$ of the respondents. Unmarried participants accounted for the majority $(55.5 \%)$ of the respondents and this is followed by married respondents which accounted for $38.3 \%$. Two hundred and thirty-six $(56.2 \%)$ participants had tertiary education and only 11 (2.6\%) respondents had no formal education. Of those who participated in the study, $140(33.3 \%)$ were students. Christianity accounted for the majority (94.8\%) of the religion of the participants and this is followed by Islam (5\%) (Table 1).

Table 1: Socio-demographic characteristics of the participants (N=420)

\begin{tabular}{|l|l|}
\hline Variable & Frequency (\%) \\
\hline Age & \\
$10-18$ & $35(8.3)$ \\
$19-25$ & $161(38.3)$ \\
$26-30$ & $96(22.9)$ \\
$31-34$ & $45(10.7)$ \\
$35-40$ & $47(11.2)$ \\
\hline
\end{tabular}




\begin{tabular}{|l|l|}
\hline$\geq 41$ & $36(8.6)$ \\
Sex & \\
Male & $219(52.1)$ \\
Female & $201(47.9)$ \\
Marital status & \\
Single & $233(55.5)$ \\
Married & $161(38.3)$ \\
Separated & $13(3.1)$ \\
Divorced & $5(1.2)$ \\
Widowed & $1(0.7)$ \\
Educational level & \\
No formal education & $11(2.6)$ \\
Primary & $25(6.0)$ \\
Secondary & $148(35.2)$ \\
Tertiary & $236(56.2)$ \\
Employment status & \\
Working full time & $118(28.1)$ \\
Working part time & $43(10.2)$ \\
Unemployed & $63(15.0)$ \\
\hline
\end{tabular}

\begin{tabular}{|l|l|}
\hline Self employed & $56(13.3)$ \\
Student & $140(33.3)$ \\
Religion & \\
African religion & $1(0.2)$ \\
Islam & $21(5.0)$ \\
Christianity & $398(94.8)$ \\
\hline
\end{tabular}

Table 2 shows different kinds of prescribed and non prescribed drugs used for non medical purposes. Pain medications such as tramadol, codeine and morphine accounted for majority (73.8\%) of unprescribed medication abused by the respondents. This is followed by other medications such as ibuprofen which was $45 \%$. Sleeping medications and stimulants accounted for $28.3 \%$ and $27.4 \%$ of unprescribed drugs respectively. Similarly, pain medication accounted for majority (74.8\%) of prescribed medicines used by the participants for non medicinal purposes. Two hundred and seventy-five $(65.4 \%)$ respondents used other prescribed medications such Ibuprofen for non medical reasons. The least abused class of drugs in the prescribed category were sedative/anxiety medications which accounted for just over $18 \%$.

Table 2: Use of drugs for non medical purposes by participants

\begin{tabular}{|l|l|l|l|l|l|}
\hline \multirow{2}{*}{ Response } & \multicolumn{5}{|c|}{ Type of drug } \\
\cline { 2 - 7 } & $\begin{array}{l}\text { Sleeping } \\
\text { medications }\end{array}$ & $\begin{array}{l}\text { Sedative/anxiety } \\
\text { medications }\end{array}$ & $\begin{array}{l}\text { Stimulant } \\
\text { medications }\end{array}$ & $\begin{array}{l}\text { Pain } \\
\text { medications }\end{array}$ & $\begin{array}{l}\text { Other prescription } \\
\text { medications }\end{array}$ \\
\hline Unprescribed drugs & $119(28.3)$ & $82(19.5)$ & $115(27.4)$ & $310(73.8)$ & $189(45.0)$ \\
Yes [n(\%)] & $301(71.7)$ & $338(80.5)$ & $305(72.6)$ & $110(26.2)$ & $231(55.0)$ \\
No [n(\%)] & & & $102(24.3)$ & $314(74.8)$ & $275(65.4)$ \\
Prescribed drugs & $110(26.2)$ & $77(18.3)$ & $318(75.8)$ & $106(25.2)$ & $145(34.6)$ \\
Yes [n(\%)] & $310(73.8)$ & $343(81.7)$ & & & \\
No [n(\%)] & &
\end{tabular}

Table 3: Pattern of non medical use of prescription medicines among participants

\begin{tabular}{|c|c|c|c|}
\hline \multirow{2}{*}{ Pattern of drug use } & \multicolumn{3}{|c|}{ Response (n\%) } \\
\hline & & Yes $(n \%)$ & No $(n \%)$ \\
\hline Approached to trade or give away prescription? & & $117(27.9)$ & $303(72.1)$ \\
\hline If yes, what type of medication? & & & \\
\hline Sleeping medicines & $30(18.6)$ & & \\
\hline Sedatives & $13(8.1)$ & & \\
\hline Stimulants & $21(13.0)$ & & \\
\hline Analgesics & $73(45.3)$ & & \\
\hline Others & $24(14.9)$ & & \\
\hline Have borrowed prescribed medications? & & $334(55.7)$ & $186(44.3)$ \\
\hline If yes, what type of medication? & & & \\
\hline Sleeping medicines & $30(7.1)$ & & \\
\hline Sedatives & $20(4.8)$ & & \\
\hline Stimulants & $25(6.0)$ & & \\
\hline Analgesics & $132(31.4)$ & & \\
\hline Others & $36(8.6)$ & & \\
\hline Have you used drugs for non medical purposes? & & $161(38.3)$ & $259(61.7)$ \\
\hline Reasons for non medical use of drugs & & & \\
\hline To relax or relieve tension & $86(20.5)$ & & \\
\hline To get high & $45(10.7)$ & & \\
\hline For recreation & $29(6.9)$ & & \\
\hline To improve concentration & $70(16.7)$ & & \\
\hline Others & $4(1.0)$ & & \\
\hline Means of getting medications for non medical use & & & \\
\hline Family & $82(19.5)$ & & \\
\hline Friends & $111(26.4)$ & & \\
\hline Theft and burglary & $17(4.0)$ & & \\
\hline Street drug dealers & $82(19.5)$ & & \\
\hline Online & $16(3.8)$ & & \\
\hline Have you called for more pain medication because prescription ran out? & & $148(35.2)$ & $272(64.8)$ \\
\hline Have used pain medications for symptoms-sleeping, anxiety, depression & & $173(41.2)$ & 247(58.8) \\
\hline
\end{tabular}


Do you save unused medications for future use?

Have you lost pain medication and needed it replaced?

Pattern of non medical use of prescription medicines among participants were shown in Table 3. One hundred and seventeen (27.9\%) respondents admitted to have been approached to sell or give away their prescription. The most commonly demanded medications were analgesics $(45.3 \%)$ and sleeping medicines $(18.6 \%)$. Over half of participants reported to have borrowed prescription medications from friends or family member and analgesics accounted for the majority (31.4\%) of borrowed prescription in this study. Over one-third of the study respondents reported to have used drugs for non medical purposes. To relax or relieve tension is the most common reasons (20.5\%) for use of drugs for non medical purposes reported in this study. Other reasons include to improve concentration $(16.7 \%)$, to get high $(10.7 \%)$ and for recreation $(6.9 \%)$. Just over one-fourth of the respondents reported to procure the medications from friends. Family members and street drug dealers accounted for $19.5 \%$ each of the source of drugs for the abusers. Theft and burglary were a source of the drug for $4 \%$ of the participants.

\section{Discussion}

The study confirmed a relatively high prevalence rate of drug use for non medical purposes in Abakaliki. The prevalence of use of drug in this study was $38.3 \%$. This was lower than the $45.3 \%$ reported in Owerri, $69.2 \%$ in Abeokuta and $78 \%$ in Ilorin but higher than the $23.7 \%$ reported in Maiduguri and $2.5 \%$ in Japan. ${ }^{[19-}$

23] These differences could be as a result of the different criteria used for diagnosis of drug use and the type of substance studied. The observed differences could also be as a result of differing methodologies and socio-cultural characteristics of the respondents. Recently, Nigerian government has instituted a strong policy for controlling the use of illicit and other psychotropic drugs. ${ }^{[24]}$ However, a recent international comparison has pointed out that punitive illegal drug policies do not necessarily correlate with low prevalence of illegal drug use, with the high prevalence in a country which has stringent policies for example the US compared to the Netherlands. ${ }^{[25,26]}$ The finding of this study seems to confirm that despite strict government policy to control illegal drug use, its use is still prevalent in our society.

The mean age of the participants was $22.2 \pm 3.8$ years with majority of them (38.3\%) being within the 19-25 years age bracket. This is similar to the result of study in Owerri (22.5 years), and Ilorin (23.9 years), and Port-Harcourt (21.3 years). ${ }^{[27-28]}$ This study shows that drug users were found to have onset before their early twenties. The present study supports a previous observation that drug use commonly starts in adolescence and young adulthood. In addition, This study observed an increase in lifetime use of drugs in Abakaliki among younger respondents, which is similar with a pattern consistently seen in many other countries, suggesting a recent worldwide epidemic of drug use in the younger generation. ${ }^{[29-32]}$ Also, this study reported a higher proportion of male respondents. Similar studies have reported a preponderance of males among drug abusers in Nigeria. The societal, cultural and attitude that seems to favour the male child could account for this. However, education of the female child has been on the rise for decades especially in south eastern part of Nigeria and thereby leading to rising number of females that abuse drugs. Although it has been reported that the male-female gap was closing in more recent cohorts. Part of male domination in drug use is attributable
205(48.8)

174(41.4)

$215(51.2)$

246(58.6)

to a possible association between violent or impulsive behaviors and drug use.

The common drugs used for non medical reasons in Abakaliki as revealed in our study were analgesics, sedatives and stimulants. This pattern of use was similar to findings of a study in Sudan but yet other workers have identified alcohol as the commonest psychoactive substance in use which was not among the substances studied in this work. Some of the reasons given for drug use by our respondents were to relax or relieve tension, to improve concentration, to get high and for recreation. These were similar to findings reported in previous studies for initiation of substance use.

About half of the respondents in this study procure their drug either from a friend or a family member. Street drug dealers accounted for $19.5 \%$ of drug source for drug abusers. This shows that elimination of street drug trade may not be effective in eliminating source of drugs for its abuser. The Several studies have identified peers and relatives as major sources of psychoactive substance initiation. ${ }^{[33-35]}$ It has been suggested that peers might serve as good role models for substance use intervention program.

There are several limitations to this study. First, the prevalence and age of onset were based on a retrospective self-report assessment that was vulnerable to recall and other information bias (such as reluctance to disclose information). In addition, the study design was a cross-sectional type and this limits its validity. A longitudinal design in which participants are followed up would be most ideal.

\section{Conclusion}

This study confirms that non medical use of drugs is common among our study participants in Abakaliki. There is need to establish and strengthen peer educators in our community. Integration of the use and consequences of non medical use of drugs into the curricula of primary and secondary schools will help to reduce the scourge of drug abuse in our community.

\section{Acknowledgement}

None

\section{Conflict of interest}

The authors declare no conflict of interests in this study.

\section{References}

[1] United Nations Office on Drugs and Crime. The nonmedical use of prescription drugs. Policy Direction Issues (Discussion 2011. https://www.unodc.org/documents/drug-preventionandtreatment/ nonmedical-use-prescription-drugs.pdf. Accessed May 22, 2019.

[2] United States, Office of National Drug Control Policy, Current State of Drug Policy: Successes and Challenges (Washington D. C., March 2008).

[3] EMCDDA Statistical Bulletin 2009. Accessed at: www.emcdda.europa.eu/stats09 
[4] United Nations Office on Drugs and Crime. Drug Use in Nigeria. UNODC; 2018.

[5] United Nations Office on Drugs and Crime. World Drug Report, United Nations Office on Drugs and Crime, Austria. UNODC, 2010.

[6] Kreek M. J, Nielsen D. A., Butelman E. R., LaForge K. S. Genetic influences on impulsivity, risk taking, stress responsivity and vulnerability to drug abuse and addiction. Nature Neuroscience. 2005; 8(11):1450-7

[7] UNODC and the Paris Pact Initiative (2008), Illicit Drug Trends in Pakistan, April 2008.

[8] EMCDDA Annual Report 2010. Accessed at: www.emcdda.europa.eu/publications/annual-report /2010

[9] International Narcotics Control Board (2009) Annual Report, retrieved from www.incb.org/ incb/en/annualreport-2009.html

[10] ESPAD. The 2007 ESPAD report. Substance use among students in 35 countries. Accessed at: www.espad.org/documents/Espad/ESPAD_reports/2007/ The_2007_ESPAD_ReportFULL_091006.pdf

[11] SAHMSA 2009 National Survey on Drug Use and Health. Results from the 2009 National Survey on Drug Use and Health: Volume I. Summary of National Findings. U.S. Department Of Health And Human Services Substance Abuse and Mental Health Services Administration Office of Applied Studies retrieved from http://oas.samhsa.gov/NSDUH/2k9NSDUH/2k9Results. htm

[12] Colliver, Compton, Wilson M., Volkow, Nora D. Commentary: Major increases in opioid analgesic abuse in the United States: Concerns and strategies. Drug and Alcohol Dependence. 2006; 81(2):103-107.

[13] Merlo LJ. Prescription Opioid Abuse and Dependence Among Physicians: Hypotheses and Treatment. Harvard Review of Psychiatry, 2008; 16 (3): 181 - 194

[14] Herman-Stahl, M. , Krebs, C. Kroutil, L. Heller, D. Risk and Protective Factors for Non-medical use of Prescription Stimulants and Methamphetamine among Adolescents. J Adolescent Health, 2018; 39(3): 374-380

[15] Gaffney A. Drug use monitoring in Australia: 2008 annual report on drug use among police detainees, Australian Institute of Criminology 2010.

[16] Edlund MJ, Martin BC, Fan MY. Risks for opioid abuse and dependence among recipients of chronic opioid therapy: Results from the TROUP Study. Drug Alcohol Depend. 2010;112:90-8

[17] Government of Nigeria. Report on 2006 Census Final Result. Federal Government of Nigeria Printer, Abuja. 2009; 96: B39. www.jstor.org/stable/ 25434601?seq=1\#page_scan_tab_contents. (Accessed February 27, 2019).

[18] Charan J, Biswas T. How to Calculate Sample Size for Different Study Designs in Medical Research? Indian J Psychol Med, 2013; 35(2): 121-126.

[19] Amin DM., Elnagdi SA. Amer SA. Drug Abuse in Zagazig University Students, Egypt: Cross Sectional Study 2018. Occupational Diseases and Environmental Medicine, 2019(7): 37-49. https://doi.org/10.4236/odem.2019.72004.

[20] Duru CB, Oluoha UR, Okafor CC, Diwe KC, Iwu AC, Aguocha CM et al. Socio-Demographic Determinants of Psychoactive Substance Use among Students of Tertiary
Institutions in Imo State, Nigeria. J Addict Res Ther. 2017(8): 345. doi:10.4172/2155-6105.1000345.

[21] Famuyiwa O, Olatunji FA, Bankole-Oki OM. Epidemiology of psychoactive drug use amongst adolescents in metropolitan Lagos, Nigeria. Eur Child Adolesc Psychiatry. 2011 20:351-359. DOI 10.1007/s00787-011-0180-6.

[22] Ekpenyong SN. Drug Abuse in Nigerian Schools: A Study of Selected Secondary Institutions in Bayelsa State, South-South, Nigeria. Int J Sci Research Education. 2012,, 5(3): 260-268.

[23] Adeyemo FO, Ohaeri B, Okpala PU, Ogodo O. Prevalence of Drug Abuse Amongst University Students in Benin City, Nigeria. Public Health Research 2016, 6(2): 31-37 DOI: 10.5923/j.phr.20160602.01.

[24] Udechukwu J, Samuel, GK. Assessment of Tramadol Abuse Predictors among Undergraduates in Ignatius Ajuru University of Education, Port Harcourt, Rivers State. Int J Recent Advances Multidisc Research, 2018;5(4):3775-3781.

[25] Australian Institute of Health and Welfare. Non-medical use of pharmaceuticals: trends, harms and treatment, 2006-07 to 2015-16. Drug treatment series 2017;30. Cat. no. HSE 195. Canberra: AIHW.

[26] Quintero G, Peterson, J, Young B. An Exploratory Study of Socio-cultural Factors Contributing to Prescription Drug Misuse among College Students. J Drug Issues, 2006; 22: 903-926.

[27] Arria AM, Caldeira KM, O'Grady KE, Vincent KB, Johnson EP, Wish ED. Non-medical use of prescription stimulants among college students: Associations with attention-deficithyperactivity disorder and polydrug use. Pharmacotherapy. 2008;28(2):156-169.

[28] National Center on Addiction and Substance Abuse. Under the Counter: The Diversion and Abuse of Controlled prescription drugs in the U. S. CASA 2005.

[29] Drugs and Crime Prevention Committee. Inquiry into the misuse/abuse of benzodiazepines and other forms of pharmaceutical drugs in Victoria: final report. Melbourne: $\quad$ www.parliament.vic.gov.au/57thparliament/dcpc/inquiries/inquiry/233.

[30] ACIC. National waste water drug monitoring program: report 1, March 2017. Canberra: ACIC 2017.

[31] CDC. Opioid overdose. Atlanta: US Department of Health and Human Services. CDC 2017.

[32] Drugs and Crime Prevention Committee. Inquiry into the misuse/abuse of benzodiazepines and other forms of pharmaceutical drugs in Victoria: final report. Melbourne: DCPC 2007.

[33] Nicholas R, Lee N, Roche A Pharmaceutical drug misuse in Australia: complex problems, balanced responses. Adelaide: National Centre for Education and Training on Addiction. 2017

[34] Humphreys K. Avoiding globalisation of the prescription opioid epidemic. The Lancet. 2017 390:437-9.

[35] Tominaga M, Kawakami N, Ono $\mathrm{Y}$, Nakane $\mathrm{Y}$, Nakamura $\mathrm{Y}$, Tachimori $\mathrm{H}$, et al. Prevalence and correlates of illicit and non-medical use of psychotropic drugs in Japan Findings from the World Mental Health Japan Survey 2002-2004. Soc Psychiatry Psychiatr Epidemiol. 2009; 44:777-783. 